\title{
PRMT1 expression predicts sensitivity to platinum-based chemotherapy in patients with ovarian serous carcinoma
}

\author{
HIROAKI MATSUBARA, TAKESHI FUKUDA, YUICHIRO AWAZU, SHIGENORI NANNO, \\ MASAHIRO SHIMOMURA, YUTA INOUE, MAKOTO YAMAUCHI, TOMOYO YASUI and TOSHIYUKI SUMI \\ Department of Obstetrics and Gynecology, Osaka City University Graduate School of Medicine, Osaka 545-8585, Japan
}

Received October 30, 2020; Accepted December 14, 2020

DOI: $10.3892 / \mathrm{ol} .2020 .12423$

\begin{abstract}
Patients with ovarian serous carcinoma are generally diagnosed at an advanced disease stage. The standard treatment for these patients is maximal debulking surgery followed by platinum-taxane combination chemotherapy. Despite initially responding well, more than half of patients become refractory to first-line chemotherapy. Upregulation of protein arginine methyltransferase 1 (PRMT1) expression has been demonstrated to methylate apoptosis signal-regulated kinase 1 and inhibit its activity, thereby contributing to chemoresistance. The present study investigated the association between PRMT1 expression and sensitivity to platinum-based chemotherapy in 51 patients with ovarian serous carcinoma (International Federation of Gynecology and Obstetrics stages III and IV), and the effect of RNA interference-mediated downregulation of PRMT1 on the sensitivity of ovarian cancer cells to cisplatin and carboplatin in vitro. Immunohistochemistry of tumor specimens was used to compare the expression levels of PRMT1, a Cell Counting Kit-8 assay and small interfering RNA transfection were performed for chemosensitivity assays, and reverse transcription-quantitative PCR was used to examine PRMT1 mRNA expression. Patients were divided into platinum-sensitive $(n=26)$ and platinum-resistant $(n=25)$ groups. PRMT1 expression was significantly lower in the platinum-sensitive group than in the platinum-resistant group ( $\mathrm{P}=0.019)$. When patients were categorized according to PRMT1 expression, those in the low PRMT1 expression group were more sensitive to platinum-based chemotherapy than those in the high PRMT1 expression group $(\mathrm{P}=0.01)$. Additionally, in vitro experiments revealed that suppression of PRMT1 expression by siRNA significantly increased the sensitivity of human ovarian serous carcinoma cells to cisplatin and
\end{abstract}

Correspondence to: Dr Takeshi Fukuda, Department of Obstetrics and Gynecology, Osaka City University Graduate School of Medicine, 1-4-3 Asahimachi, Abeno-ku, Osaka 545-8585, Japan E-mail: takeshif@med.osaka-cu.ac.jp

Key words: ovarian serous carcinoma, protein arginine methyltransferase 1, chemotherapy, cisplatin, carboplatin, predictive marker carboplatin $(\mathrm{P}<0.05)$. In conclusion, PRMT1 expression could predict sensitivity to platinum-based chemotherapy in patients with ovarian serous carcinoma.

\section{Introduction}

Ovarian serous carcinoma has the highest mortality among the gynecological cancers $(1,2)$. In general, patients with malignant ovarian tumors are diagnosed at an advanced stage (stage III or IV) because of the initial lack of specific symptoms or biomarkers (3). The standard treatment for advanced ovarian serous carcinoma is maximal debulking surgery followed by platinum-taxane combination chemotherapy (4). Despite a good initial response to chemotherapy, many patients become resistant to first-line drugs and the prognosis for these individuals is particularly poor (5). The effect of re-treatment with platinum-based chemotherapy at the time of relapse depends on the duration of platinum non-use, which is defined as the time between last platinum administration and relapse (6). If the duration between last platinum administration and recurrence is less than 6 months, the cancer is defined as platinum-resistant, and if it is longer than 6 months, it is defined as platinum-sensitive (7).

Sensitivity to platinum-based chemotherapy is one of the major prognostic factors for ovarian serous carcinoma (8), and prediction of platinum sensitivity is therefore of great importance for the development of treatment strategies for patients with this disease. Unfortunately, however, no effective methods currently exist to predict platinum sensitivity in ovarian serous carcinoma. Effective prediction of platinum-sensitivity would enable the selection of only those patients who represent good candidates for platinum treatment, while sparing resistant patients the adverse side-effects associated with these drugs. Therefore, it is important to identify specific biomarkers that predict platinum sensitivity to improve patient prognosis in ovarian serous carcinoma.

Protein arginine methyltransferase 1 (PRMT1) is the major arginine methyltransferase in mammalian cells and is required for normal embryonic development, cell cycle progression, cell viability, and signaling (9-12). PRMT1 has also been reported to be a driver of tumorigenesis and tumor progression (13), and to contribute to chemotherapy resistance by methylating apoptosis signal-regulated kinase 1 (ASK1) (14).

In this study, we evaluated the association between PRMT1 expression and sensitivity to platinum-based chemotherapy 
in ovarian serous carcinoma. Our aim was to identify new biomarkers and explore new treatment options to improve the prognosis of patients with platinum-resistant disease.

\section{Materials and methods}

Patients and samples. We reviewed 51 cases of stage III or IV serous ovarian cancer in patients aged 75 and under treated at the Osaka City University Hospital between January 2005 and December 2013. Patients were assigned to one of two groups according to their platinum sensitivity. Patients assigned to the platinum-sensitive group $(n=26)$ had received chemotherapy with platinum after maximal tumor debulking surgery and had no tumor recurrence within 6 months of the date of the last platinum dose. Patients assigned to the platinum-resistant group $(n=25)$ had received platinum-based chemotherapy after maximal debulking surgery and had tumor recurrence within 6 months of the date of the last platinum dose. The study was approved by the Institutional Review Board (IRB) of Osaka City University Hospital after written informed consent was obtained from all patients prior to treatment (IRB no. 4247).

Immunohistochemistry. PRMT1 expression in ovarian serous carcinoma specimens was determined by immunohistochemical analysis of paraffin-embedded tissue sections using the Dako LSAB2 peroxidase kit (cat. no. K0675; Agilent Technologies, Inc.). Four-micron-thick tissue sections were deparaffinized, rehydrated, and soaked in 3\% hydrogen peroxide for $10 \mathrm{~min}$ at room temperature to block endogenous peroxidase activity. Antigen retrieval was performed by autoclaving sections in $10 \mathrm{mM}$ citrate buffer $\left(\mathrm{pH} \mathrm{6.0)}\right.$ at $110^{\circ} \mathrm{C}$ for $20 \mathrm{~min}$. After washing with phosphate-buffered saline (PBS), sections were incubated overnight at $4^{\circ} \mathrm{C}$ in a $1: 100$ dilution of rabbit polyclonal antibody against PRMT1 (cat. no. ab-70724; Abcam). Sections were washed with PBS for 15 min and incubated with biotinylated goat IgG secondary antibody (Dako; Agilent Technologies, Inc.) for $10 \mathrm{~min}$. Additional sections were incubated with streptavidin-peroxidase complexes and 3,3'-diaminobenzidine was used as a chromogen. Finally, all sections were stained with hematoxylin. As a control, primary antibodies were omitted to examine the specificity of the immunohistochemical reaction.

PRMT1 expression scoring was calculated by multiplying the percentage score of positive tumor cells by the staining intensity score using the weighted scores method of Sinicrope et al (15). The percentage score of positive tumor cells was defined as follows: $0(<5 \%), 1(5-25 \%), 2(25-50 \%)$, $3(50-75 \%)$, and $4(>75 \%)$. The staining intensity was scored as follows: 0 (no staining), 1 (weak staining), 2 (moderate staining), or 3 (strong staining).

Cell culture. The human ovarian serous carcinoma cell line OVSAHO (cat. no. JCRB1046; National Institute of Biomedical Sciences) was cultured in RPMI medium (Gibco; Thermo Fisher Scientific, Inc.), supplemented with $10 \%$ fetal bovine serum (Gibco; Thermo Fisher Scientific, Inc.), penicillin $(100 \mathrm{U} / \mathrm{ml})$ and streptomycin $(100 \mathrm{U} / \mathrm{ml})$, and the medium was changed every other day. Cell cultures were maintained at $37^{\circ} \mathrm{C}$ in a humidified incubator containing a $5 \% \mathrm{CO}_{2}$ atmosphere. After collection, cells were stored at $-80^{\circ} \mathrm{C}$ for subsequent analysis by reverse transcription-quantitative PCR (RT-qPCR).

Chemosensitivity assay and siRNA transfection. OVSAHO cells were seeded in 96-well plates at 3,000 cells per well and divided into groups that were transfected with or without PRMT1-specific siRNA (siPRMT1). Transfection was performed using Lipofectamine RNAiMax (Invitrogen; Thermo Fisher Scientific, Inc.).

The siPRMT1 sense sequence was 5'-GCAACUCCAUGU UUCAUAAtt-3', and the antisense sequence was 5'-UUAUGA AACAUGGAGUUGCgg-3'. After $24 \mathrm{~h}$ of culture in the presence or absence of siPRMT1, cell cultures received fresh medium containing cisplatin at concentrations of 0 , $5.0,10$, or $50 \mu \mathrm{M}$, or carboplatin at concentrations of 0,50 , 100 , or $150 \mu \mathrm{M}$, and then cultured for an additional $48 \mathrm{~h}$. To confirm cell viability, $10 \mu \mathrm{l}$ of CCK- 8 and $100 \mu \mathrm{l}$ of RPMI were added to each well using the Cell Counting kit-8 (CCK-8; Dojindo Molecular Technologies, Inc.). The plate was then incubated at $37^{\circ} \mathrm{C}$ for $2 \mathrm{~h}$ and the absorbance subsequently measured at $450 \mathrm{~nm}$ using a microplate reader (Corona Electric Co., Ltd.). Dose-response curves were prepared to determine the percentage of viable cells relative to the untreated control.

$R T$ - $q P C R$. Total RNA was extracted from OVSAHO cells using the RNeasy Mini kit (QIAGEN GmbH). RNA was reverse-transcribed using the High Capacity cDNA Reverse Transcription kit (Thermo Fisher Scientific, Inc.) and PRMT1 mRNA expression was determined using the TaqMan Gene Expression Assay and an ABI 7500 Fast Real-Time PCR System (Applied Biosystems; Thermo Fisher Scientific, Inc.). mRNA levels were normalized to those of the GAPDH house-keeping control. The TaqMan PRMT1 (Hs01587651_g1) and GAPDH (Hs99999905_m1) assays were used for RT-qPCR assays (Thermo Fisher Scientific, Inc.). The $2^{-\Delta \Delta \mathrm{Cq}}$ method was used to analyze the relative changes in gene expression for RT-qPCR experiments (16).

Statistical analysis. Data are presented as means \pm standard deviation in the tables and means \pm standard error in the figures. Prognosis was assessed by Kaplan-Meier and log-rank analysis. Weighted scores were analyzed using the Mann-Whitney test and the receiver operating characteristic (ROC) curve. The Student's t-test was used to assess the significance of the difference between the mean values of the two groups and the $\chi^{2}$ test or Fisher's exact test was used appropriately to identify significant associations between the categorical variables of the two groups. Analyses were performed with EZR (Saitama Medical Center, Jichi Medical University, Saitama, Japan). A P value $<0.05$ was considered as statistically significant.

\section{Results}

Patient characteristics. When the association between age, FIGO stage, CA125 level, and postoperative residual disease was examined, only the size of postoperative residual disease was significantly higher in the platinum-resistant group ( $\mathrm{P}=0.005$; Table I). 
Table I. Patient characteristics for the platinum-sensitive and platinum-resistant groups.

\begin{tabular}{|c|c|c|c|}
\hline Variable & Platinum-sensitive group & Platinum-resistant group & P-value \\
\hline No. of cases & 26 & 25 & \\
\hline Age, years $($ mean $\pm S D)$ & $60.4 \pm 11.7$ & $58.5 \pm 8.6$ & $0.521^{\mathrm{a}}$ \\
\hline FIGO stage, $n$ & & & $0.418^{\mathrm{b}}$ \\
\hline IIIA & 1 & 0 & \\
\hline IIIB & 3 & 1 & \\
\hline IIIC & 20 & 18 & \\
\hline IVA & 1 & 3 & \\
\hline IVB & 1 & 3 & \\
\hline Tumor marker CA125, U/ml (mean) & $3,467.6$ & $2,057.4$ & $0.309^{\mathrm{a}}$ \\
\hline Postoperative residual disease, $\mathrm{n}$ & & & $0.005^{\mathrm{b}}$ \\
\hline None & 5 & 0 & \\
\hline$\leq 1 \mathrm{~cm}$ & 8 & 2 & \\
\hline$>1 \mathrm{~cm}$ & 13 & 23 & \\
\hline
\end{tabular}

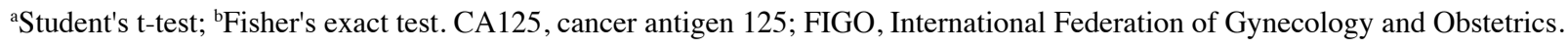

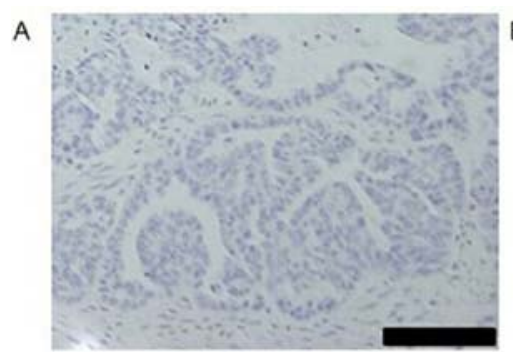

D

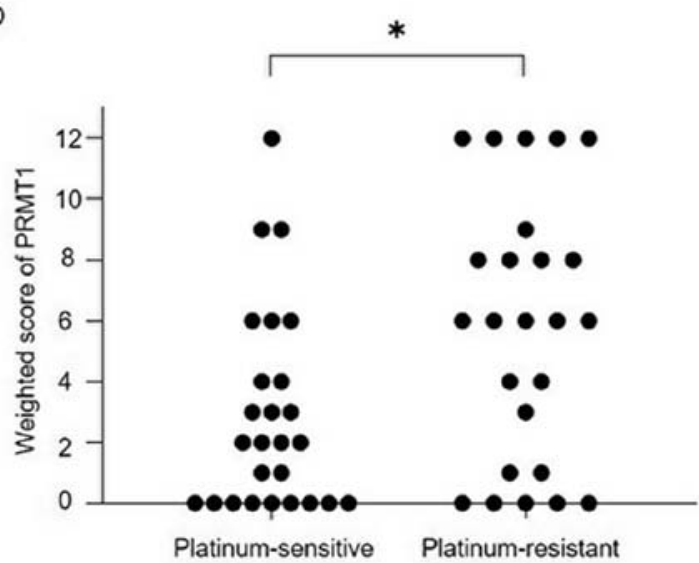

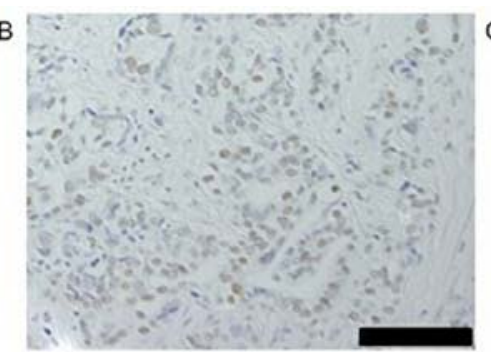

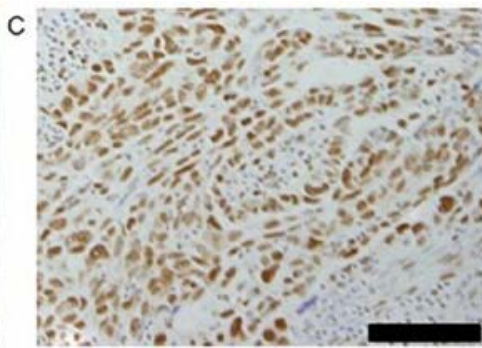

E

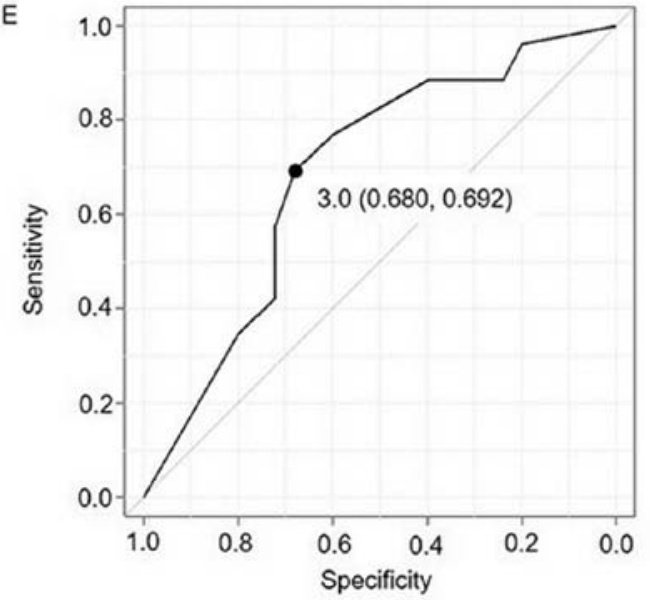

Figure 1. Immunohistochemical analysis of PRMT1 expression in ovarian serous carcinoma. (A) Negative control (no primary antibody). Tissue sections assigned scores of (B) 6 and (C) 12, following labeling with primary antibody against PRMT1. Scale bars, $100 \mu \mathrm{m}$. (D) Weighted score for PRMT1 expression in cancerous samples. PRMT1 expression was significantly higher in the platinum-resistant group than in the platinum-sensitive group. ${ }^{*} \mathrm{P}=0.019$ (Mann-Whitney U test). (E) Receiver operating characteristic curve for determining the PRMT1 score cut-off to evaluate the sensitivity to platinum-based chemotherapy. Using a cutoff value of 3 , the specificity was $68.0 \%$, and the sensitivity was $69.2 \%$. The area under the curve was 0.689 and the $95 \%$ confidence interval was $0.540-0.838$. PRMT1, protein arginine methyltransferase 1 .

Expression of PRMT1 in ovarian serous carcinoma tissue. Fig. 1 shows PRMT1 expression in cancer tissues, the weighted scores for the platinum-sensitive and resistant groups and the ROC curve for determining the PRMT1 score cut-off to evaluate the sensitivity to platinum-based chemotherapy. The weighted score for PRMT1 expression in the platinum-resistant group was significantly higher than that obtained for the platinum-sensitive group $(\mathrm{P}=0.019)$. From the ROC curve, the cut-off value was set to 3 , with a specificity of $68.0 \%$ and a sensitivity of $69.2 \%$. Based on this cut-off value, cases were 
Table II. Characteristics of the patients in the low and high PRMT1 expression groups.

\begin{tabular}{|c|c|c|c|}
\hline Variable & Low PRMT1 $(\leq 3)$ group & High PRMT1 ( $\geq 4)$ group & P-value \\
\hline No. of cases & 26 & 25 & \\
\hline Age, years (mean $\pm S D)$ & $62.3 \pm 9.2$ & $56.5 \pm 10.7$ & $0.488^{\mathrm{a}}$ \\
\hline FIGO stage, $\mathrm{n}$ & & & $0.945^{\mathrm{b}}$ \\
\hline IIIA & 0 & 1 & \\
\hline IIIB & 2 & 2 & \\
\hline IIIC & 19 & 19 & \\
\hline IVA & 2 & 2 & \\
\hline IVB & 3 & 1 & \\
\hline Tumor marker CA125, U/ml (mean) & $3,799.7$ & $1,712.0$ & $0.129^{\mathrm{a}}$ \\
\hline Postoperative residual disease, $\mathrm{n}$ & & & $0.068^{\mathrm{b}}$ \\
\hline None & 4 & 1 & \\
\hline$\leq 1 \mathrm{~cm}$ & 6 & 4 & \\
\hline$>1 \mathrm{~cm}$ & 16 & 20 & \\
\hline
\end{tabular}

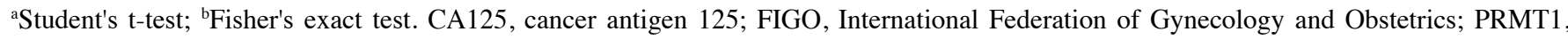
protein arginine methyltransferase 1 .

Table III. Numbers of patients with low and high PRMT1 expression in the platinum-sensitive and platinum-resistant groups.

\begin{tabular}{|c|c|c|c|}
\hline PRMT1 expression & Platinum-sensitive, n (\%) & Platinum-resistant, n (\%) & P-value \\
\hline Low, $\leq 3$ & $18(69.2)$ & $8(30.8)$ & $0.012^{\mathrm{a}}$ \\
\hline High, $\geq 4$ & $8(32.0)$ & $17(68.0)$ & \\
\hline
\end{tabular}

${ }^{\mathrm{a}} \chi^{2}$ test. PRMT1, protein arginine methyltransferase 1.

assigned to either a low PRMT1 expression group (weighted score $\leq 3, n=26$ ) or a high PRMT1 expression (weighted score $\geq 4, n=25$ ), according to their weighted score. There were no significant differences in age, stage, CA125 value, and postoperative residual lesion between the low PRMT1 expression and high PRMT1 expression groups (Table II).

Association of platinum sensitivity with PRMT1 expression. The proportion of patients sensitive to platinum-based chemotherapy was significantly higher in the low PRMT1 expression group, when compared with the high PRMT1 expression group ( $\mathrm{P}=0.01$, Table III). In the low PRMT1 expression group, $18(69.2 \%)$ cases were platinum-sensitive and $8(30.8 \%)$ cases were platinum-resistant; in the high PRMT1 expression group, $8(32.0 \%)$ cases were platinum-sensitive and 17 (68.0\%) cases were platinum-resistant.

Survival. Overall survival (OS) was significantly longer for patients of the low PRMT1 expression group than for patients of the high PRMT1 expression group ( $\mathrm{P}=0.031$, Fig. 2).

siRNA-mediated silencing of PRMT1 expression enhances the sensitivity of ovarian carcinoma cells to platinum-based therapy. PRMT1 mRNA expression in OVSAHO cells was

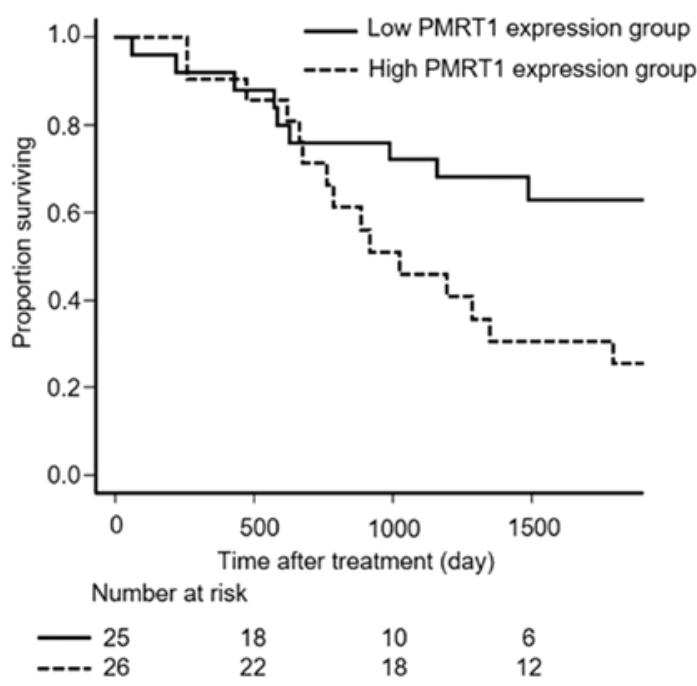

Figure 2. Overall survival for patients in the low and high PRMT1 expression groups. $\mathrm{P}=0.031$ (Kaplan-Meier and log-rank test). PRMT1, protein arginine methyltransferase 1 .

suppressed $48 \mathrm{~h}$ after transfection with siPRMT1, and cells transfected with siPRMT1 were significantly more sensitive to cisplatin or carboplatin (Fig. 3). 
A

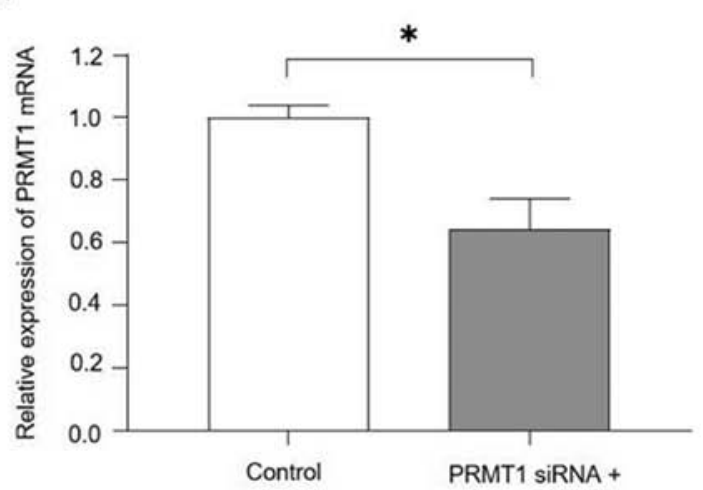

B

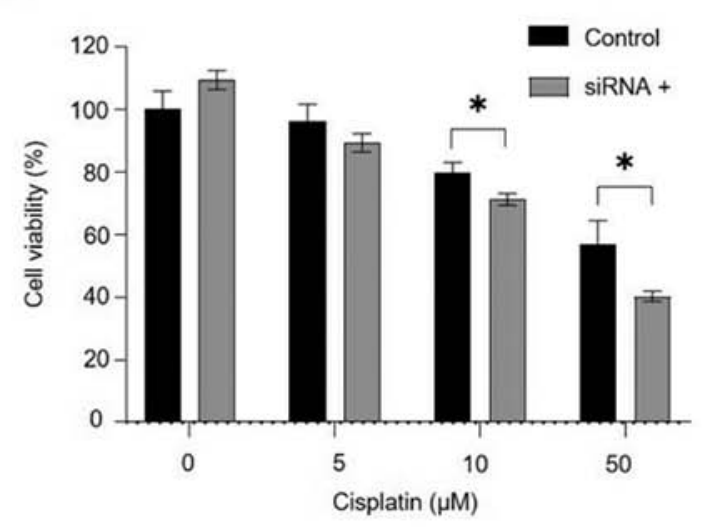

C

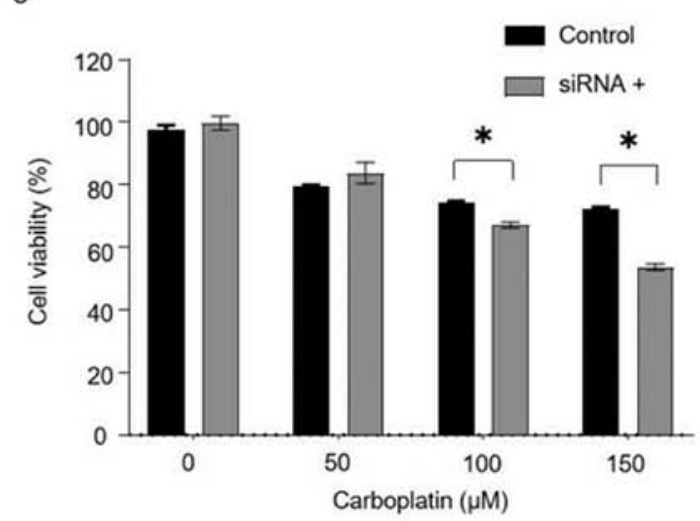

Figure 3. Effects of inhibition of PRMT1 expression on OVSAHO ovarian serous cancer cell sensitivity to platinum-based chemotherapeutic agents (A) PRMT1 mRNA expression was significantly decreased following transfection with PRMT1-targeting siRNA. ${ }^{*} \mathrm{P}<0.05$ (Student's t-test). PRMT1 mRNA levels were normalized to those of GAPDH. (B) Sensitivity of OVSAHO cells to cisplatin in the presence or absence of an siRNA specific for PRMT1. "P<0.05 (Student's t-test). (C) Sensitivity of OVSAHO cells to carboplatin in the presence or absence of an siRNA specific for PRMT1 ${ }^{*} \mathrm{P}<0.05$ (Studen's t-test). PRMT1, protein arginine methyltransferase 1; siRNA, small interfering RNA.

\section{Discussion}

Effective treatment for serous ovarian cancer remains a major challenge because of platinum-resistant recurrence. It has been suggested that mechanisms of platinum-resistance may involve decreased cellular import and increased cellular export of the drug by transporter proteins, intracellular drug inactivation by detoxifying enzymes, enhanced DNA damage repair, and inactivation of cell death signaling. In platinum-resistant tumor cells, multiple mechanisms may be involved simultaneously (17-19).

Arginine methylation is a major regulator of protein function in mammalian cells (9). PRMT1 represents the major arginine methyltransferase in mammalian cells and is required for normal embryonic development, cell division and cell viability (9-12). PRMT1 is involved in signaling pathways that regulate DNA damage, mRNA translation, cell cycle progression, apoptosis, and genes transcription (20-24).

PRMT1 has been implicated in the development and progression of a variety of diseases, including cancer, cardiovascular disease, diabetes, and fat production in the liver (25-29). There are several reports regarding PRMT1 expression or involvement in a variety of cancers, including colorectal, breast, lung, bladder, liver, esophageal and head and neck cancers $(13,30-35)$.

PRMT1 has been shown to methylate cytoplasmic proteins involved in the regulation of apoptotic signaling. It is also associated with cell cycle arrest during the G0/G1 phase. In addition, PRMT1 has been shown to methylate ASK1 and inhibit its activity (36). Studies have also shown that knockdown of PRMT1 promotes a PI3K-Akt signaling pathway-dependent suppression of oxidative stress-induced apoptosis, and that inhibition of PRMT1 attenuates activation of the NF- $x \mathrm{~B}$ pathway, making cells more susceptible to chemotherapeutic agents $(37,38)$.

In this study, OS was significantly longer in the low PRMT1 expression group, when compared with the high PRMT1 expression group. siRNA-mediated suppression of PRMT1 expression increased the sensitivity of OVSAHO cells to cisplatin and carboplatin. Overexpression of PRMT1 may inhibit cell death by inhibiting the activation of ASK1, thereby reducing the effects of chemotherapy. Despite studies showing an association between PRMT1 expression and poor cancer prognosis, the mechanism by which PRMT1 induces resistance to chemotherapy remains unclear. Although our study included only 51 cases, the clinical data suggest that PRMT1 expression may be a prognostic factor for poor outcome in serous ovarian cancer. More studies which includes elucidating the mechanism of ASK1 are now needed to confirm the role of PRMT1 as a prognostic marker in serous ovarian cancer. To this end, ASK1 is known to be methylated and inhibited the activity by PRMT1, therefore we are planning the experiment to elucidate the enhanced apoptosis induced by carboplatin or cisplatin when ASK1 is depleted by RNAi resulting in higher sensitivity to those chemotherapeutic agents.

In conclusion, our data suggest that PRMT1 expression may be a predictive marker of the efficacy of platinum-based chemotherapy in patients with serous ovarian cancer. To our knowledge, this is the first report of an association between PRMT1 expression and platinum sensitivity, and these findings should facilitate future studies that aim to improve the prognosis of patients with serous ovarian cancer.

\section{Acknowledgements}

The authors would like to thank Dr Mary Derry and Dr James Monypenny for editing a draft of this manuscript. 


\section{Funding}

The present study was supported by The Osaka Medical Research Foundation for Intractable Diseases (grant no. 26-2-47).

\section{Availability of data and materials}

The datasets used and/or analyzed during the current study are available from the corresponding author on reasonable request.

\section{Authors' contributions}

TF and TS designed the current study. TF and HM assessed the authenticity of all the raw data. HM, YI, SN, YA, MS and MY performed the experiments and collected the data. TF, HM, TY and TS analyzed the data. TF and HM wrote the manuscript. All authors read and approved the final manuscript.

\section{Ethics approval and consent to participate}

The present study was approved by the Institutional Review Board of Osaka City University Hospital (IRB no. 4247; Osaka, Japan) before initiation of the study. Written informed consent was obtained from all patients.

\section{Patient consent for publication}

Patient consent for publication was not obtained. However, the data included in the present study does not compromise anonymity or confidentiality or breach local data protection laws.

\section{Competing interests}

The authors declare that they have no competing interests.

\section{References}

1. Jemal A, Bray F, Center MM, Ferlay J, Ward E and Forman D Global cancer statistics. CA Cancer J Clin 61: 69-90, 2011.

2. Borley J, Wilhelm-Benartzi C, Brown R and Ghaem-Maghami S: Does tumour biology determine surgical success in the treatment of epithelial ovarian cancer? A systematic literature review. Br J Cancer 107: 1069-1074, 2012.

3. $\mathrm{du}$ Bois A, Quinn M, Thigpen T, Vermorken J, Avall-Lundqvist E, Bookman M, Bowtell D, Brady M, Casado A, Cervantes A, et al; Gynecologic Cancer Intergroup, AGO-OVAR, ANZGOG, EORTC, GEICO, GINECO, GOG, JGOG, MRC/NCRI, NCIC-CTG, NCI-US, NSGO, RTOG, SGCTG, IGCS, Organizational team of the two prior International OCCC: 2004 consensus statements on the management of ovarian cancer: Final document of the 3rd International Gynecologic Cancer Intergroup Ovarian Cancer Consensus Conference (GCIG OCCC 2004). Ann Oncol 16 (Suppl 8): viii7-viii12, 2005

4. Japan Society of Gynecologic Oncology: Formulation committee of the treatment guidelines for ovarian. https://jsgo. or.jp/guideline/ransou2015.html. Accessed September 1, 2017.

5. Ozols RF, Bundy BN, Greer BE, Fowler JM, Clarke-Pearson D, Burger RA, Mannel RS, DeGeest K, Hartenbach EM and Baergen R; Gynecologic Oncology Group: Phase III trial of carboplatin and paclitaxel compared with cisplatin and paclitaxel in patients with optimally resected stage III ovarian cancer: A Gynecologic Oncology Group study. J Clin Oncol 21: 3194-3200, 2003.
6. Friedlander M, Trimble E,Tinker A,Alberts D, Avall-LundqvistE, Brady M, Harter P, Pignata S, Pujade-Lauraine E, Sehouli J, et al; Gynecologic Cancer InterGroup: Clinical trials in recurrent ovarian cancer. Int J Gynecol Cancer 21: 771-775, 2011.

7. Markman M, Rothman R, Hakes T, Reichman B, Hoskins W, Rubin S, Jones W, Almadrones L and Lewis JL Jr: Second-line platinum therapy in patients with ovarian cancer previously treated with cisplatin. J Clin Oncol 9: 389-393, 1991.

8. Kyrgiou M, Salanti G, Pavlidis N, Paraskevaidis E and Ioannidis JP: Survival benefits with diverse chemotherapy regimens for ovarian cancer: Meta-analysis of multiple treatments. J Natl Cancer Inst 98: 1655-1663, 2006.

9. Spriggs KA, Bushell M and Willis AE: Translational regulation of gene expression during conditions of cell stress. Mol Cell 40: 228-237, 2010

10. Truitt ML and Ruggero D: New frontiers in translational control of the cancer genome. Nat Rev Cancer 16: 288-304, 2016. Erratum in: Nat Rev Cancer 17: 332, 2017.

11. Marcel V, Catez F and Diaz JJ: p53, a translational regulator: Contribution to its tumour-suppressor activity. Oncogene 34: 5513-5523, 2015.

12. Wooderchak WL, Zang T, Zhou ZS, Acuña M, Tahara SM and Hevel JM: Substrate profiling of PRMT1 reveals amino acid sequences that extend beyond the 'RGG' paradigm. Biochemistry 47: 9456-9466, 2008.

13. Yoshimatsu M, Toyokawa G, Hayami S, Unoki M, Tsunoda T, Field HI, Kelly JD, Neal DE, Maehara Y, Ponder BA, et al: Dysregulation of PRMT1 and PRMT6, type I arginine methyltransferases, is involved in various types of human cancers. Int $\mathrm{J}$ Cancer 128: 562-573, 2011.

14. Hirata Y, Katagiri K, Nagaoka K, Morishita T, Kudoh Y, Hatta T, Naguro I, Kano K, Udagawa T, Natsume T, et al: TRIM48 promotes ASK1 activation and cell death through ubiquitination-dependent degradation of the ASK1-negative regulator PRMT1. Cell Rep 21: 2447-2457, 2017.

15. Sinicrope FA, Ruan SB, Cleary KR, Stephens LC, Lee JJ and Levin B: bcl-2 and p53 oncoprotein expression during colorectal tumorigenesis. Cancer Res 55: 237-241, 1995.

16. Livak KJ and Schmittgen TD: Analysis of relative gene expression data using real-time quantitative PCR and the 2(-Delta Delta C(T)) method. Methods 25: 402-408, 2001.

17. Dasari S and Tchounwou PB: Cisplatin in cancer therapy: Molecular mechanisms of action. Eur J Pharmacol 740: 364-378, 2014.

18. Ghosh S. Cisplatin: The first metal based anticancer drug. Bioorg Chem 88: 102925, 2019.

19. Amable L: Cisplatin resistance and opportunities for precision medicine. Pharmacol Res 106: 27-36, 2016.

20. Infantino S, Benz B, Waldmann T, Jung M, Schneider R and Reth M: Arginine methylation of the B cell antigen receptor promotes differentiation. J Exp Med 207: 711-719, 2010.

21. Sakamaki J, Daitoku H, Ueno K, Hagiwara A, Yamagata K and Fukamizu A: Arginine methylation of BCL-2 antagonist of cell death (BAD) counteracts its phosphorylation and inactivation by Akt. Proc Natl Acad Sci USA 108: 6085-6090, 2011.

22. Yu Z, Chen T, Hébert J, Li E and Richard S: A mouse PRMT1 null allele defines an essential role for arginine methylation in genome maintenance and cell proliferation. Mol Cell Biol 29: 2982-2996, 2009. Erratum in: Mol Cell Biol 37: e00298-17, 2017.

23. Dominguez-Sola D, Kung J, Holmes AB, Wells VA, Mo T, Basso K and Dalla-Favera R: The FOXO1 transcription factor instructs the germinal center dark zone program. Immunity 43: 1064-1074, 2015.

24. Kuhn P, Chumanov R, Wang Y, Ge Y, Burgess RR and Xu W: Automethylation of CARM1 allows coupling of transcription and mRNA splicing. Nucleic Acids Res 39: 2717-2726, 2011.

25. Kim DI, Park MJ, Choi JH, Kim IS, Han HJ, Yoon KC, Park SW, Lee MY, Oh KS and Park SH: PRMT1 and PRMT4 regulate oxidative stress-induced retinal pigment epithelial cell damage in SIRT1-dependent and SIRT1-independent manners. Oxid Med Cell Longev 2015: 617919, 2015.

26. Mathioudaki K, Papadokostopoulou A, Scorilas A, Xynopoulos D, Agnanti N and Talieri M: The PRMT1 gene expression pattern in colon cancer. Br J Cancer 99: 2094-2099, 2008.

27. Park MJ, Kim DI, Lim SK, Choi JH, Kim JC, Yoon KC, Lee JB, Lee JH, Han HJ, Choi IP, et al: Thioredoxin-interacting protein mediates hepatic lipogenesis and inflammation via PRMT1 and PGC-1 $\alpha$ regulation in vitro and in vivo. J Hepatol 61: 1151-1157, 2014. 
28. Siroen MP, Teerlink T, Nijveldt RJ, Prins HA, Richir MC and van Leeuwen PA: The clinical significance of asymmetric dimethylarginine. Annu Rev Nutr 26: 203-228, 2006.

29. Sydow K, Mondon CE and Cooke JP: Insulin resistance: Potential role of the endogenous nitric oxide synthase inhibitor ADMA. Vasc Med 10 (Suppl 1): S35-S43, 2005.

30. Li B, Liu L, Li X and Wu L: miR-503 suppresses metastasis of hepatocellular carcinoma cell by targeting PRMT1. Biochem Biophys Res Commun 464: 982-987, 2015.

31. Zhou W, Yue H, Li C, Chen H and Yuan Y: Protein arginine methyltransferase 1 promoted the growth and migration of cancer cells in esophageal squamous cell carcinoma. Tumour Biol 37: 2613-2619, 2016.

32. Chuang CY, Chang CP, Lee YJ, Lin WL, Chang WW, Wu JS, Cheng YW, Lee H and Li C: PRMT1 expression is elevated in head and neck cancer and inhibition of protein arginine methylation by adenosine dialdehyde or PRMT1 knockdown downregulates proliferation and migration of oral cancer cells. Oncol Rep 38: 1115-1123, 2017.

33. Avasarala S, Van Scoyk M, Karuppusamy Rathinam MK, Zerayesus S, Zhao X, Zhang W, Pergande MR, Borgia JA, DeGregori J, Port JD, et al: PRMT1 is a novel regulator of epithelial-mesenchymal-transition in non-small cell lung cancer. J Biol Chem 290: 13479-13489, 2015.
34. Baldwin RM, Bejide M, Trinkle-Mulcahy L and Côté J: Identification of the PRMT1v1 and PRMT1v2 specific interactomes by quantitative mass spectrometry in breast cancer cells. Proteomics 15: 2187-2197, 2015.

35. Papadokostopoulou A, Mathioudaki K, Scorilas A, Xynopoulos D, Ardavanis A, Kouroumalis E and Talieri M: Colon cancer and protein arginine methyltransferase 1 gene expression. Anticancer Res 29: 1361-1366, 2009.

36. Cho JH, Lee MK, Yoon KW, Lee J, Cho SG and Choi EJ: Arginine methylation-dependent regulation of ASK1 signaling by PRMT1. Cell Death Differ 19: 859-870, 2012.

37. Baldwin RM, Morettin A and Côté J: Role of PRMTs in cancer: Could minor isoforms be leaving a mark? World J Biol Chem 5: 115-129, 2014.

38. Musiani D, Giambruno R, Massignani E, Ippolito MR, Maniaci M, Jammula S, Manganaro D, Cuomo A, Nicosia L, Pasini D and Bonaldi T: PRMT1 is recruited via DNA-PK to chromatin where it sustains the senescence-associated secretory phenotype in response to cisplatin. Cell Rep 30: 1208-1222.e9, 2020. 